\title{
Impact of an integrated care program on glycemic control and cardiovascular risk factors in patients with type 2 diabetes in Saudi Arabia: an interventional parallel- group controlled study
}

Ayla M. Tourkmani, Osama Abdelhay, Hesham I. Alkhashan, Aboud F. Alaboud, Ahmed Bakhit, Tarek Elsaid, Ahmed Alawad, Aljohara Alobaikan, Hala Alqahtani, Abdulaziz Alqahtani, Adel Mishriky, Abdulaziz bin Rsheed and Turki J. Alharbi ${ }^{*}$

\begin{abstract}
Background: Long intervals between patient visits and limited time with patients can result in clinical inertia and suboptimal achievement of treatment goals. These obstacles can be improved with a multidisciplinary care program. The present study aimed to assess the impact of such a program on glycemic control and cardiovascular risk factors.

Methods: In a randomized, parallel-group trial, we assigned 263 patients with poorly controlled type 2 diabetes mellitus (T2DM) to either a control group, standard care program, or a multidisciplinary care program involving a senior family physician, clinical pharmacy specialist, dietician, diabetic educator, health educator, and social worker. The participants were followed for a median of 10 months, between September 2013 and September 2014. Glycated hemoglobin ( $\mathrm{HbA1c}$ ), fasting blood glucose (FBG), lipid profiles, and blood pressure (BP) were measured. The assignment was blinded for the assessors of the study outcomes. The study registry number is.

Results: In the intervention group, there were statistically significant $(p<0.05)$ post-intervention (relative) reductions in the levels of HbA1c $(-27.1 \%, 95 \% \mathrm{Cl}=-28.9 \%,-25.3 \%)$, FBG $(-17.10 \%, 95 \% \mathrm{Cl}=-23.3 \%,-10.9 \%)$, total cholesterol $(-9.93 \%, 95 \% \mathrm{Cl}=-12.7 \%,-7.9 \%), \mathrm{LDL}$ cholesterol $(-11.4 \%, 95 \% \mathrm{Cl}=-19.4 \%,-3.5 \%)$, systolic BP $(-1.5 \%, 95 \% \mathrm{Cl}=-2.9 \%$, $-0.03 \%)$, and diastolic $\mathrm{BP}(-3.4 \%, 95 \% \mathrm{Cl}=-5.2 \%,-1.7 \%)$. There was a significant decrease in the number of patients with a HbA1c $\geq 10(86 \mathrm{mmol} / \mathrm{mol})$ from 167 patients at enrollment to 11 patients after intervention $(p<0.001)$. However, the intervention group experienced a statistically significant increase in body weight $(3.7 \%, 95 \% \mathrm{Cl}=2.9 \%, 4.5 \%)$. In the control group, no statistically significant changes were noticed in different outcomes with the exception of total cholesterol $(-4.10 \%, p=0.07)$. In the linear regression model, the intervention and the total number of clinic visits predicted $\mathrm{HbA} 1 \mathrm{c}$ improvement.
\end{abstract}

Conclusions: Implementation of a patient-specific integrated care program involving a multidisciplinary team approach, frequent clinic visits, and intensified insulin treatment was associated with marked improvement in glycemic control and cardiovascular risk factors of poorly controlled T2DM patients in a safe and reproducible manner.

Trial registration: ISRCTN Identifier: ISRCTN83437562 September 19, 2016 Retrospectively registered.

Keywords: Type 2 diabetes, Cardiovascular risk, Glycemic control, Multidisciplinary care

\footnotetext{
* Correspondence: turkifcm@yahoo.com

Family and Community Medicine Department, Prince Sultan Military Medical

City, P.O. Box 7897, Riyadh 11159, Saudi Arabia
} 


\section{Background}

Saudi Arabia has one of the highest rates of diabetes in the world [1]. Local population studies estimate the prevalence of diabetes at approximately 24\% among Saudi adults [2]. This is approximately three times the world average [1]. A recent epidemiologic forecast study that incorporated the high obesity and smoking prevalence trends among Saudi adults estimated type 2 diabetes mellitus (T2DM) at 44\% in 2022 [3]. In addition to the associated increased risk of morbidity and mortality, T2DM among Saudis has led to a surge in healthcare utilization and allocated costs [4]. Diabetes is known to increase the risk of vascular diseases such as heart diseases and stroke markedly [5]. This can be averted, or at least delayed, by intensive glycemic control [6, 7], along with the control of associated risk factors such as hypertension and dyslipidemia [7-9]. However, the compliance with these preventive measures by patients with T2DM is inadequate $[10,11]$.

Primary care physicians manage most patients with T2DM. However, long intervals between patient visits and limited time with patients can result in clinical inertia and, consequently, suboptimal achievement of treatment goals [12, 13]. Several strategies have been described to overcome barriers to efficient diabetes management at primary care settings, including a multidisciplinary team approach $[12,14]$. The implementation of such an approach was successful in improving diabetes care in primary care patients [15]. We have reported a successful integrated care program for improving diabetes management in Saudi Arabia [16]. However, the small sample size and the lack of control limited the inferences from the study findings. The aim of the current study was to evaluate the impact of a multidisciplinary diabetic care program on glycated hemoglobin (HbA1c) and cardiovascular risk factors among patients with poorly controlled T2DM in a primary care setting, using a controlled interventional design. The study assessed changes in HbA1c, fasting blood glucose (FBG), total cholesterol, triglycerides, HDL cholesterol, LDL cholesterol, systolic and diastolic blood pressure (BP), body weight, number of visits, and record of concomitant medications and the frequency of adjustment.

\section{Methods}

\section{Setting}

The study was conducted in Al-Wazarat Chronic Diseases Center, a division of the Al-Wazarat Health Care (WHC) Family Medicine Center in Riyadh, Saudi Arabia. The Chronic Diseases Center consists of 12 specialized clinics, primarily for patients with T2DM, hypertension, dyslipidemia, and bronchial asthma, in addition to a procedures room and support services such as pharmacy, laboratory, and radiology. The Chronic Diseases
Center is staffed by senior family physicians who are board certified and/or specialized in diabetes care, a board certified clinical pharmacist, dieticians, diabetic educators, health educators, and social workers. The daily clinics are run by six physicians serving approximately 120 patients daily.

\section{Design}

A randomized, controlled interventional study was conducted between September 2013 and September 2014. Enrollment data were assessed by reviewing the patient charts for at least two visits before joining the study. Outcome data were assessed by prospectively following patients for at least two visits after joining the study (for a maximum of 9 months). Controls were recruited from the same center using the same eligibility criteria. All required ethical approvals from the local ethical committee were obtained before data collection.

\section{Population and eligibility}

The study sample was recruited from adult patients, 18 years or older, with T2DM who received their diabetic care at the Chronic Diseases Center of WHC. Patients who had at least two clinic visits before joining the study and were able to provide informed consent were checked for eligibility for enrollment. Patients who received care from both diabetes clinics at the endocrinology department and primary care clinics were excluded to avoid double care and to assure a standardized level of management. The eligibility criteria included one or more of the following: (1) poor glycemic control (HbA1c $>10[86 \mathrm{mmol} / \mathrm{mol}]$ or persistent elevation of HbA1c $>8$ [64 mmol/mol] for 1 year or more); (2) failure to respond to therapeutic insulin dose of $>2$ units $/ \mathrm{kg}$ or 200 units irrespective of weight; (3) inadequate adherence to insulin; (4) uncontrolled hypertension or hyperlipidemia with maximum possible combination of medications; (5) comorbidity such as cardiovascular, renal, or hepatic disease; and (6) inadequate continuity of care (such as recurrent missed appointments for insulin titration). The eligible patients were consecutively assigned to either the intervention or control groups using a computerized random number generator. The 289 patients were assigned unique study numbers ranging from 1 to 289. The number assigned was consistent with the recruitment date (i.e., the first patient recruited was assigned the number 1 and the last patient recruited was assigned the number 289). The clinical pharmacist who acted as the case manager conducted assigned study numbers. The biostatistician generated a random sequence of 72 numbers out of 289 using a computer program without knowing the order of the patients. The case manager assigned the patients' numbers who matched those on the random sequence to the control 
group. The recruitment and randomization processes of the patients are illustrated in Fig. 1.

\section{Sample size}

Considering the results of the pilot study, we proposed that an integrated care program can reduce HbA1c by 3 points and FBG by $3 \mathrm{mmol} / \mathrm{L}$. To detect a 2-point difference in $\mathrm{HbA1c}$ (3.0 versus 1.0 with a standard deviation [SD] of 2.7) between the intervention and control groups with $80 \%$ power and $95 \%$ confidence, 80 patients were required (60 in the intervention and 20 in the control group, assuming a ratio of 3:1). Similarly, to detect a difference of $2 \mathrm{mmol} / \mathrm{L}$ in FBG (3.0 versus 1.0 with a SD of 5.0) between the intervention and control groups with $80 \%$ power and $95 \%$ confidence, 264 patients were required (198 in the intervention and 66 in the control group, assuming a ratio of 3:1). Therefore, the larger sample size was adopted. The researchers opted to select a smaller size for the control group compared with the intervention (1 to 3 ) to maximize the number of patients gaining potential benefits from the intervention.

\section{Outcome}

The absolute and relative changes in the levels of HbA1c, FBG, blood lipids (total, LDL, HDL cholesterol, and triglycerides), BP (systolic and diastolic), and body weight during the study relative to baseline were the outcomes measured.

\section{Intervention}

The integrated care program is a multidisciplinary program used for the care of patients in the intervention group. Patients were referred from any discipline working in the Chronic Diseases Center when they fulfilled the eligibility criteria for the integrated care program to the case manager. The program team included a senior family physician, clinical pharmacy specialist who acted as a case manager, dietician, diabetic educator, health educator, and social worker. The program team met once or twice weekly to review the eligibility of referred patients and to assess and decide on the care plans for those who had already been enrolled. The care provided was the standard care per the guidelines of the American Diabetes Association (ADA) [17], but intensified with consideration for individual clinical and social factors. The case manager was responsible for arranging required appointments with other specialties as per the care plan, as well as evaluating the compliance and adverse effects of the new plan, through at least weekly appointments in the first 3 months. Enrolled patients had

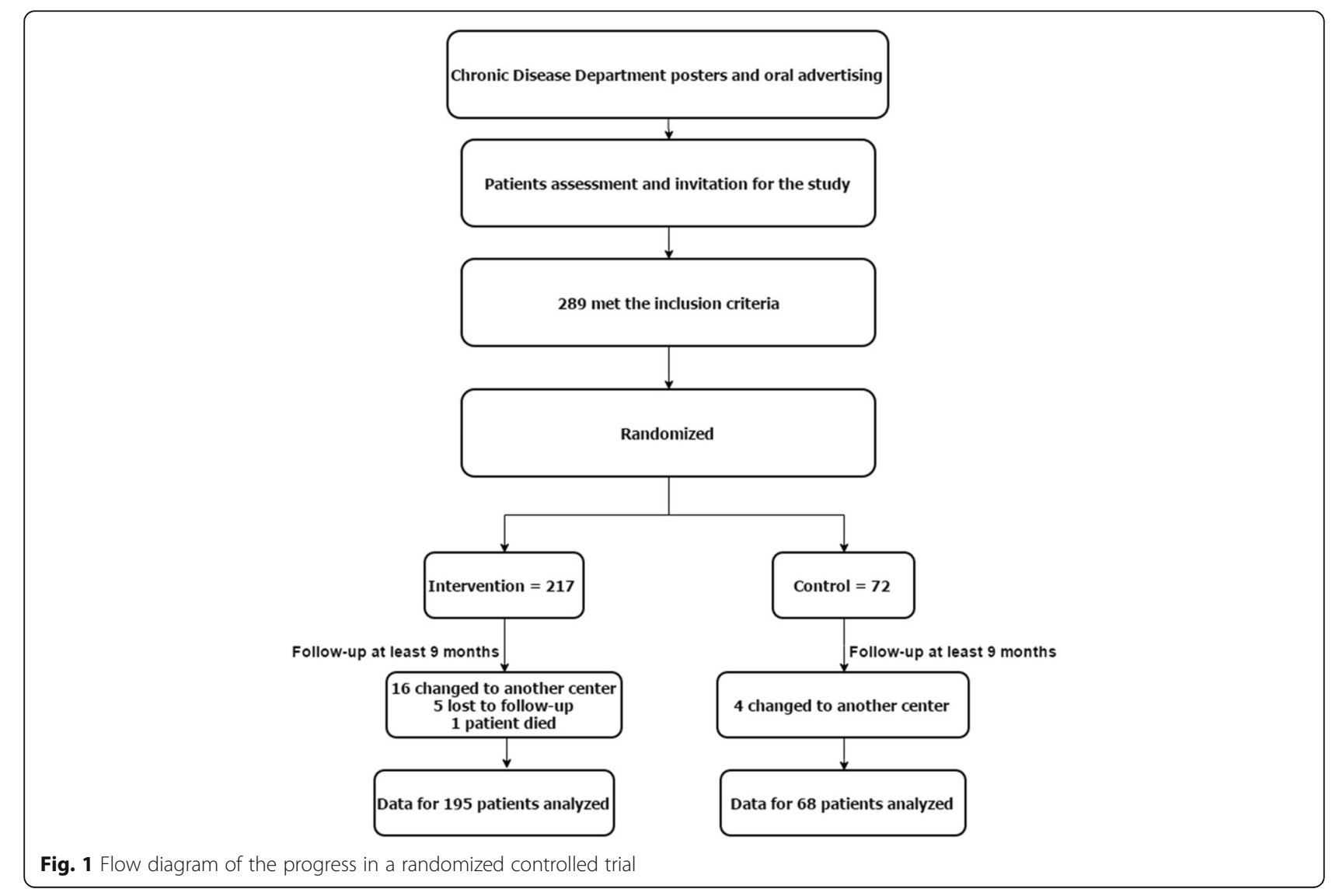


to be seen at least once by all members of the program team during the period of enrollment, with the exception of the social worker who was seen on an as-needed basis. Strategies to improve the care were patient-based and included (but not limited to) providing more clinic visits, frequent monitoring of outcomes, improving multidisciplinary communication and coordination, providing additional diabetic education and dietetic advice, promoting self-management, providing a booklet for home blood glucose monitoring, adjusting doses according hepatic and renal functions, assessing the need and performing insulin titration, encouraging medication adherence, providing social support, sending patients reminders, and making telephone calls $[12,14,18]$.

\section{Standard care}

The care provided to the patients in the control group was congruent with the ADA guidelines [17] with regular appointments every 3 months in the Chronic Disease Clinics. (Additional file 1: Table S1). The intervention is illustrated in Fig. 2.

\section{Statistical methods}

Patients' characteristics are described as means and SDs for continuous data and frequencies and percentages for categorical data. Significant differences between the intervention and control groups were tested using a Student's $t$-test or Mann-Whitney test (as appropriate) for continuous data and chi-square test or Fisher's exact test (as appropriate) for categorical data. The percentage of change in the study outcomes was defined as the amount of change during the study relative to baseline at enrollment. The change in the levels of the study outcomes was examined using a paired $t$-test. The correlations between the change in HbA1c and the patient's age and clinical and management factors were examined using Spearman's correlation. Independent predictors of $\mathrm{HbA1c}$ change were evaluated using a multivariate linear regression model. All $p$-values were two-tailed. $P$-values $<0.05$ were considered significant. SPSS software (release 20.0, SPSS Inc., Chicago, U.S.) was used for all statistical analyses.

\section{Results}

The final study analysis included 263 patients with T2DM, with 195 patients in the intervention group and 68 patients in the control group. The demographic and clinical characteristics of both groups at the study enrollment are described in Table 1 . The mean age was roughly similar in both groups $(56.9 \pm 12.0$ years in the intervention group versus $57.7 \pm 11.6$ years in the control group). Females similarly represented the majority of patients in both groups (65.6\% versus 63.2\%). The intervention group had a significantly lower number of comorbidities compared with the control group ( $2.3 \pm 0.8$ versus 3.0 $\pm 1.0, p<0.001$ ), with lower rates of hypertension $(30.3 \%$ versus $70.6 \%, \quad p<0.001)$ and dyslipidemia $(46.2 \%$ versus $95.6 \%, p<0.001)$. However, the intervention group had significantly higher body weights $(82.9 \pm 17.6$ versus $74.8 \pm 14.3, p<0.001)$ and $\mathrm{HbA1c}$

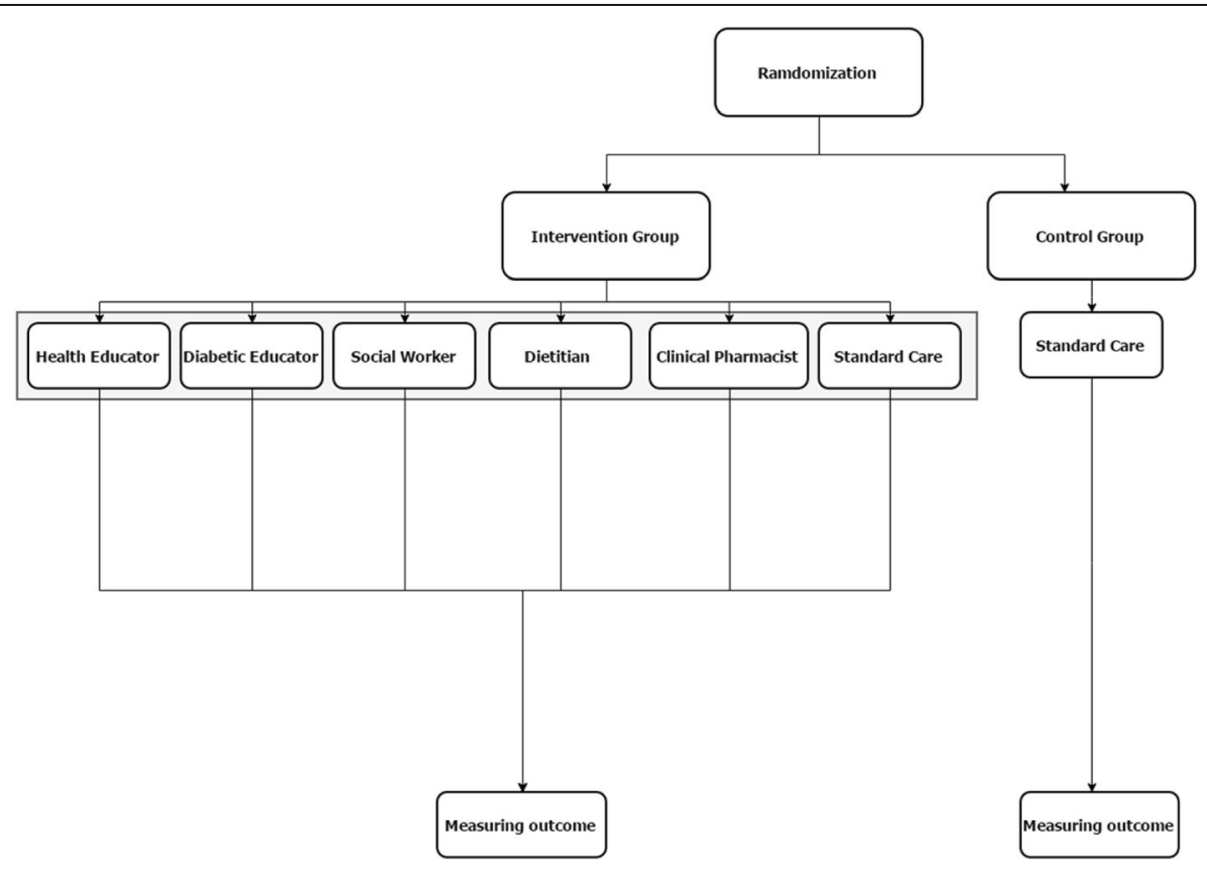

Fig. 2 Graphical depiction of the intervention 
Table 1 Demographic and clinical data of the study groups at enrollment

\begin{tabular}{|c|c|c|c|}
\hline & $\begin{array}{l}\text { Intervention } \\
(N=195)\end{array}$ & $\begin{array}{l}\text { Control } \\
(N=68)\end{array}$ & $p$-value ${ }^{a}$ \\
\hline \multicolumn{4}{|l|}{ Age (years) } \\
\hline$<50$ & $47(24.1 \%)$ & $15(22.1 \%)$ & \\
\hline $50-59$ & $68(34.9 \%)$ & $22(32.4 \%)$ & \\
\hline$\geq 60$ & $80(41.0 \%)$ & $31(45.6 \%)$ & \\
\hline Range & $20-85$ & $33-83$ & \\
\hline Mean $\pm S D^{b}$ & $56.9 \pm 12.0$ & $57.7 \pm 11.6$ & 0.649 \\
\hline \multicolumn{4}{|l|}{ Sex } \\
\hline Male (92) & $67(34.4 \%)$ & $25(36.8 \%)$ & 0.720 \\
\hline Female (171) & $128(65.6 \%)$ & $43(63.2 \%)$ & \\
\hline \multicolumn{4}{|l|}{ Comorbidities } \\
\hline Number ${ }^{\mathrm{b}}$ & $2.3 \pm 0.8$ & $3.0 \pm 1.0$ & $<0.001$ \\
\hline Hypertension & 59 (30.3\%) & $48(70.6 \%)$ & $<0.001$ \\
\hline Dyslipidemia & $90(46.2 \%)$ & 65 (95.6\%) & $<0.001$ \\
\hline Cardiac disease & $33(16.9 \%)$ & $9(13.2 \%)$ & 0.475 \\
\hline Cerebrovascular disease & $4(2.1 \%)$ & $0(0.0 \%)$ & 0.234 \\
\hline Renal disease & $29(14.9 \%)$ & $9(13.2 \%)$ & 0.741 \\
\hline Hypothyroidism & $28(14.4 \%)$ & $8(11.8 \%)$ & 0.592 \\
\hline Others & $4(2.1 \%)$ & $0(0.0 \%)$ & 0.234 \\
\hline Diabetes Duration ${ }^{\mathrm{b}}$ (years) & $1.21 \pm 0.3$ & $1.16 \pm 0.3$ & 0.238 \\
\hline Body weight $(\mathrm{Kg})^{\mathrm{b}}$ & $82.9 \pm 17.6$ & $74.8 \pm 14.3$ & $<0.001$ \\
\hline \multicolumn{4}{|l|}{ Glycemic control $^{\ddagger}$} \\
\hline HbA1c (\%) & $11.2 \pm 1.4$ & $10.1 \pm 1.6$ & $<0.001$ \\
\hline $\mathrm{HbA1c}(\mathrm{mmol} / \mathrm{mol})$ & $99 \pm(84-114)$ & $87 \pm(69-104)$ & \\
\hline $\begin{array}{l}\text { Fasting blood glucose } \\
(\mathrm{mmol} / \mathrm{l})\end{array}$ & $12.3 \pm 4.6$ & $12.2 \pm 4.3$ & 0.865 \\
\hline \multicolumn{4}{|l|}{ Blood lipids $\left(\mathrm{mmol} / \mathrm{l}^{\ddagger}\right.$} \\
\hline Total cholesterol & $4.7 \pm 1.3$ & $5.0 \pm 4.1$ & 0.292 \\
\hline Triglycerides & $1.9 \pm 1.9$ & $1.6 \pm 0.7$ & 0.102 \\
\hline HDL cholesterol & $1.2 \pm 0.3$ & $1.1 \pm 0.3$ & 0.506 \\
\hline LDL cholesterol & $2.7 \pm 1.0$ & $2.7 \pm 0.9$ & 0.979 \\
\hline \multicolumn{4}{|l|}{ Blood pressure $(\mathrm{mmHg})^{b}$} \\
\hline Systolic & $130.1 \pm 13.3$ & $129.1 \pm 14.1$ & 0.600 \\
\hline Diastolic & $73.2 \pm 8.0$ & $74.0 \pm 8.2$ & 0.481 \\
\hline
\end{tabular}

asing Chi-square unless mentioned otherwise

${ }^{\mathrm{b}}$ Student $t$-test

$(11.2 \pm 1.4[99 \mathrm{mmol} / \mathrm{mol}(84-114)]$ versus $10.1 \pm 1.6$ ( $87 \mathrm{mmol} / \mathrm{mol}[69-104], p<0.001)$ compared with the control group. Both groups had similar levels of fasting blood glucose, blood lipids, and blood pressure.

Diabetes management in the two study groups is described in Additional file 1: Table S1. The patients in the intervention group had significantly higher insulin use (97.4\% versus $63.2 \%, p<0.001)$, more mixed insulin types $(91.3 \%$ versus $33.8 \%, p<0.001)$, more insulin with multiple daily doses $(p<0.001)$, and more total insulin daily dose per $\mathrm{kg}(1.3 \pm 0.7$ versus $0.6 \pm 0.4, p<0.001)$ compared with the control group. They also had significantly higher total number of visits $(11.9 \pm 6.6$ versus $5.1 \pm 4.8, p<0.001$ ), as well as visits to a case manager, diabetes educator, and health educator compared with the control group.

The enrollment and final levels, as well as the changes in the study outcomes, are shown in Table 2. In the intervention group, there were significant decreases in the percentage of change relative to baseline in the levels of HbA1c $(-27.08 \%, p<0.001)$, FBG $(-17.0 \%, p<0.001)$, total cholesterol $(-9.93 \%, p<0.001)$, LDL cholesterol $(-11.44 \%, p=0.005)$, systolic BP $(-1.49 .0 \%, p=0.046)$, and diastolic BP $(-3.410 \%, p<0.001)$ but significant relative increase in body weight $(3.72 \%, p<0.001)$. In the control group, there were no significant changes during the study in the levels of different outcomes with the exception of the reduction in total cholesterol $(-4.10 \%$, $p=0.007)$. Moreover, the reductions in HbA1c, FBG, total cholesterol, and, to a lesser extent, LDL cholesterol, as well as the increase in body weight, observed in the intervention group were significantly higher than respective changes in the control group.

The change in HbA1c in both study groups is further illustrated in Fig. 3a and b. In the intervention group, there was a clear reduction in the number of patients with $\mathrm{HbA} 1 \mathrm{c} \geq 10 \%(86 \mathrm{mmol} / \mathrm{mol}$ ) (from 167 patients at enrollment to only 11 patients after intervention). This was accompanied by an increase in the number of patients with $\mathrm{HbAlc}<7 \%$ (53 mmol/mol) (from none to 36 patients). The number of the patients with different HbA1c categories in the control group remained relatively constant during the study (Fig. 3a). None of the patients in the intervention group had a worsened HbA1c and those who had a two- or three-category improvement of their $\mathrm{HbA1c}$ were all patients in the intervention group, except for two participants. Those who had no change in their HbA1c category represented $12 \%$ $(n=23)$ of the intervention group and $56 \%(n=38)$ of the control group (Fig. 3b).

The potential correlates of $\mathrm{HbA1c}$ improvement were examined in Table 3. In both groups combined, such improvement was positively and significantly correlated with the number of insulin types used, total insulin daily dose per $\mathrm{kg}$, number of all medications used, and total number of clinic visits (including visits to the case manager, diabetes educator, and health educator) but negatively and significantly correlated with the number of comorbidities and visits to a doctor or dietitian. When each group was examined separately, improvement was positively and significantly correlated only with the total number of clinic visits and visits to a case manager in the intervention group but none in the control group. In 
Table 2 Paired post-pre changes (as a percent of the baseline) in HbA1c, blood glucose and lipids, blood pressure and body weight among patients in the intervention and control groups

\begin{tabular}{|c|c|c|c|c|c|c|c|}
\hline & $\begin{array}{l}\text { Mean } \pm \text { SD of difference of relative } \\
\text { changes related to start of the study }\end{array}$ & & Lower confidence & Upper confidence & $\begin{array}{l}\text { Paired } \\
\text { t-test }\end{array}$ & $d f$ & $P$-value \\
\hline \multicolumn{8}{|l|}{ Intervention } \\
\hline $\mathrm{HbA1c}$ & $-27.08 \pm 12.90$ & & -25.26 & -28.90 & -29.31 & 194 & $<0.001^{*}$ \\
\hline $\mathrm{FBG}$ & $-17.10 \pm 43.38$ & & -10.91 & -23.29 & -5.45 & 190 & $<0.001^{*}$ \\
\hline Cholesterol & $-9.93 \pm 19.05$ & & -7.19 & -12.66 & -7.16 & 188 & $<0.001^{*}$ \\
\hline Triglycerides & $-3.84 \pm 50.39$ & & 3.35 & -11.03 & -1.05 & 190 & 0.294 \\
\hline $\mathrm{HDL}$ & $6.56 \pm 51.96$ & & 13.98 & -0.85 & 1.75 & 190 & 0.082 \\
\hline LDL & $-11.44 \pm 56.35$ & & -3.46 & -19.42 & -2.83 & 193 & $0.005^{*}$ \\
\hline Systolic BP & $-1.49 \pm 10.36$ & & -0.03 & -2.95 & -2.01 & 194 & $0.046^{*}$ \\
\hline Diastolic BP & $-3.41 \pm 12.34$ & & -1.67 & -5.15 & -3.86 & 194 & $<0.001^{*}$ \\
\hline Body weight & $3.72 \pm 5.62$ & & 4.54 & 2.91 & 9.01 & 184 & $<0.001^{*}$ \\
\hline \multicolumn{8}{|l|}{ Control } \\
\hline $\mathrm{HbA1c}$ & 18.75 & 122.04 & 48.29 & -10.79 & 1.27 & 67 & 0.210 \\
\hline FBG & -0.74 & 49.16 & 11.16 & -12.64 & -0.12 & 67 & 0.901 \\
\hline Cholesterol & -4.10 & 11.28 & -1.16 & -7.04 & -2.79 & 58 & $0.007^{*}$ \\
\hline Triglycerides & 0.73 & 37.52 & -9.82 & 8.35 & 0.16 & 67 & 0.873 \\
\hline $\mathrm{HDL}$ & -0.21 & 13.56 & 3.07 & -3.49 & -0.13 & 67 & 0.897 \\
\hline $\mathrm{LDL}$ & -1.65 & 41.20 & 8.33 & -11.62 & -0.33 & 67 & 0.743 \\
\hline Systolic BP & 1.18 & 10.48 & 3.72 & -1.35 & 0.93 & 67 & 0.356 \\
\hline Diastolic BP & -0.11 & 12.19 & 2.85 & -3.06 & -0.07 & 67 & 0.944 \\
\hline Body weight & 0.16 & 4.44 & 1.24 & -0.92 & 0.30 & 66 & 0.766 \\
\hline
\end{tabular}

$\left(^{*}\right)$ Statistically significant at $p<0.05$. The relative change was calculated as the mean change during the study divided by the mean at enrollment

a multivariate linear regression model that included all significant correlates with HbA1c improvement as shown above, only being in the intervention group (additional $2.47 \% \mathrm{HbA} 1 \mathrm{c}$ reduction as compared with the control group) and the total number of clinic visits (0.07\% HbA1c reduction per visit) were significantly associated with HbA1c improvement (Table 4). These two variables alone explained $35 \%$ of the change in HbA1c levels. (Table 5).

\section{Discussion}

A successful integrated diabetic care program was achieved among a group of patients with poorly controlled T2DM. The program resulted in a considerable improvement of glycemic control and, to a lesser extent, cardiovascular risk factors. Similarly, a number of studies reported improved glycemic control and cardiovascular risk profile at primary care settings after implementing a multidisciplinary care approach, intensifying patient education and modifying workflow to allow better access $[15,19,20]$.

The observed reduction in HbA1c in the current study (3.1\% absolute and $27.08 \%$ relative) was higher than observed in similar studies in the primary care setting $[15,19,20]$. Additionally, a review of studies that implemented intensified diabetic care by a multidisciplinary team, including a primary care physician and clinical pharmacist with an advanced practice nurse, showed between 0.4 and $2.1 \%$ improvement in HbA1c levels [12].

The observed higher improvement in the current study may be explained by the relatively worse diabetic control at enrollment (approximately $85 \%$ of the intervention group had $\mathrm{HbA} 1 \mathrm{c} \geq 10[86 \mathrm{mmol} / \mathrm{mol}])$. Those with poor diabetic control in the current study and other studies were the highest group to benefit from the integrated care program [21]. Nevertheless, comparisons of the current findings with other studies may be methodologically challenging as the intensity and frequency of the care provided as well as the composition of the multidisciplinary team markedly varied between different studies. We believe that the observed reduction in $\mathrm{HbA1c}$, if maintained, can result in considerable reductions in cardiovascular morbidity and mortality, as well as the cost of diabetic care $[22,23]$.

The lack of glycemic control and poor control of cardiovascular risk factors among patients in the control group was not surprising. The majority of Saudi patients with T2DM who receive regular diabetic care at primary care centers, outpatient clinics of internal medicine, or 


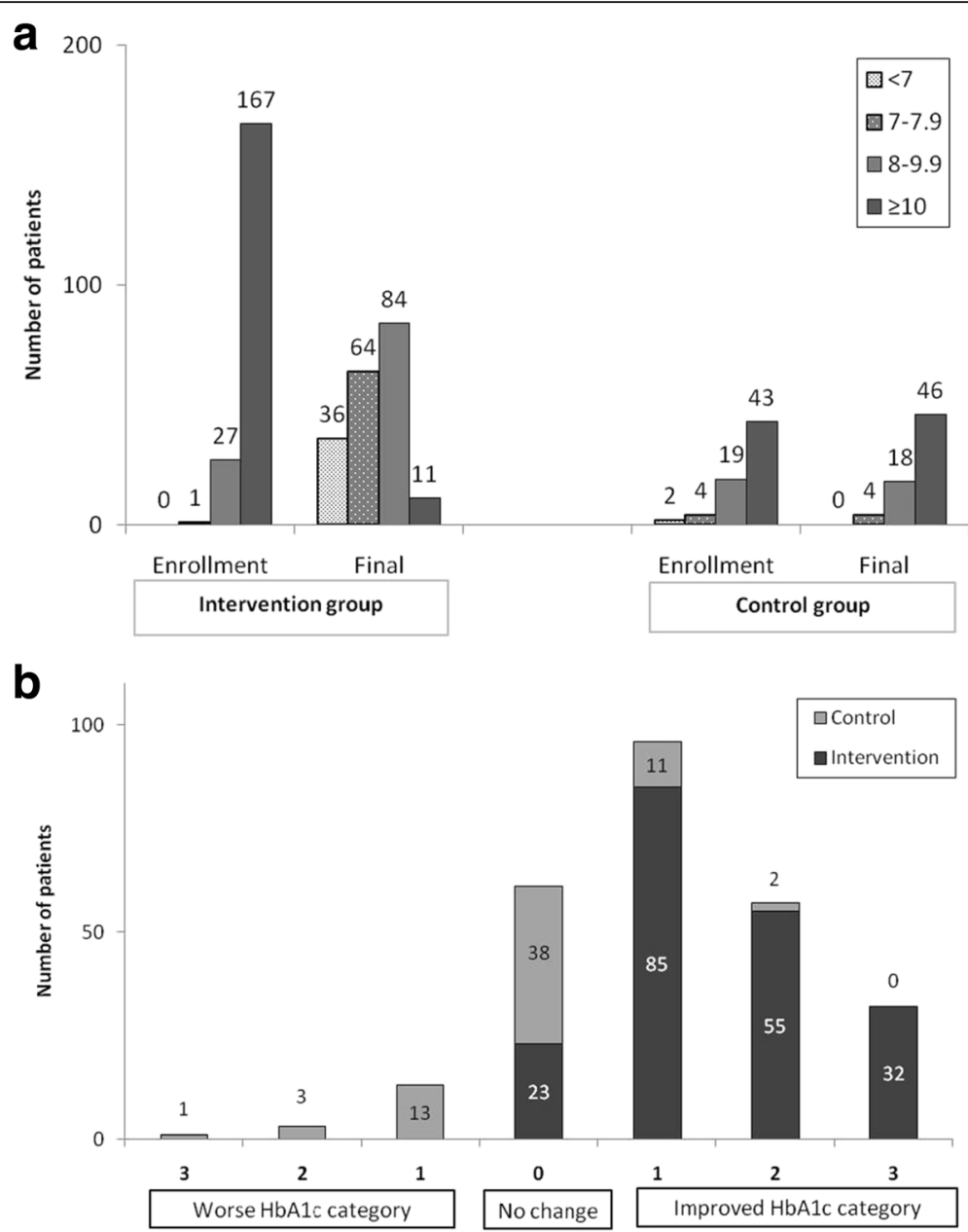

Fig. 3 a Comparison of different categories of $\mathrm{HbA1c}$ at enrollment and final stage of follow up. $\mathbf{b}$ Change in HbA1c category for both the intervention and control cohorts

Table 3 Absolute difference at the end of the study between intervention and control group, showed statistically significant difference in HbA1c, FBG, Cholesterol, LDL and Body weight parameters with $P$ value $(<0.001,0.012,0.024,0.033$ and $<0.001)$ respectively

\begin{tabular}{|c|c|c|c|c|}
\hline $\begin{array}{l}\text { Modifiable } \\
\text { risk factors }\end{array}$ & $\begin{array}{l}\text { Intervention final measurement } \\
\text { at the end of study (mean } \pm \text { SD) }\end{array}$ & $\begin{array}{l}\text { Control final measurement at } \\
\text { the end of study (mean } \pm \text { SD) }\end{array}$ & $\begin{array}{l}\text { Absolute difference at the end of study } \\
\text { between intervention and control }\end{array}$ & $\mathrm{P}^{\dagger}$ Value \\
\hline $\mathrm{HbA1c}$ & $8.0 \pm 1.2$ & $11.7 \pm 11.3$ & 3.7 & $0.001^{*}$ \\
\hline FBG & $9.3 \pm 4.5$ & $11.2 \pm 4.5$ & 1.9 & $0.005^{*}$ \\
\hline Cholesterol & $4.1 \pm 0.8$ & $4.8 \pm 4.1$ & 7 & $0.022^{*}$ \\
\hline Triglycerides & $1.6 \pm 0.9$ & $1.5 \pm 0.6$ & .1 & 0.233 \\
\hline $\mathrm{HDL}$ & $1.2 \pm 0.3$ & $1.1 \pm 0.3$ & .1 & 0.914 \\
\hline LDL & $2.1 \pm 0.6$ & $2.5 \pm 0.9$ & .4 & 0.059 \\
\hline Systolic BP & $127.5 \pm 13$ & $129.7 \pm 11.4$ & 2.2 & 0.223 \\
\hline Diastolic BP & $70.3 \pm 9.2$ & $73.3 \pm 7.8$ & 3 & 0.215 \\
\hline Body weight & $85.7 \pm 17.8$ & $74.9 \pm 14.8$ & 10.8 & $0.001^{*}$ \\
\hline
\end{tabular}

$\dagger-P$ values for the intervention-control differences were estimated using $\dagger$ the Mann-Whitney $U$ test ${ }^{*} \mathrm{P}<0.05$ 
Table 4 Correlation between the pre-post changes in HbA1c levels and certain patients' personal and disease and service characteristics

\begin{tabular}{|c|c|c|c|c|c|c|}
\hline & & & Spearman rank & correlation & & \\
\hline & Total & & Intervention & & Control & \\
\hline & $\begin{array}{l}\mathrm{HbA1c} \\
\text { (pre-post diff) }\end{array}$ & $\begin{array}{l}\mathrm{HbA} 1 \mathrm{c} \\
\text { (pre-post diff \% of pre) }\end{array}$ & $\begin{array}{l}\text { HbAlc } \\
\text { (pre-post diff) }\end{array}$ & $\begin{array}{l}\text { HbA1c } \\
\text { (pre-post diff \% of pre) }\end{array}$ & $\begin{array}{l}\text { HbA1c } \\
\text { (pre-post diff) }\end{array}$ & $\begin{array}{l}\text { HbA1c } \\
\text { (pre-post diff \% of pre) }\end{array}$ \\
\hline $\begin{array}{l}\text { HbA1c } \\
\text { (pre-post diff \% of pre) }\end{array}$ & $.992 \S$ & & $.984^{\S}$ & & $.997^{\S}$ & \\
\hline Age & -0.03 & -0.02 & -0.03 & -0.01 & 0.07 & 0.07 \\
\hline Duration of DM & -0.11 & -0.10 & -0.11 & -0.10 & -0.54 & -0.54 \\
\hline $\begin{array}{l}\text { Insulin total } \\
\text { dose/kg Number of: }\end{array}$ & $.177^{\S}$ & $.172^{\S}$ & 0.00 & -0.01 & -0.01 & -0.02 \\
\hline Comorbidities & $-.229^{\S}$ & $-.232^{\S}$ & 0.03 & 0.03 & -0.02 & -0.01 \\
\hline Insulin types & $.423^{\S}$ & $.427^{\S}$ & -0.04 & -0.05 & 0.21 & 0.21 \\
\hline Oral drugs & 0.08 & 0.07 & 0.02 & 0.00 & -0.05 & -0.03 \\
\hline $\begin{array}{l}\text { All medications } \\
\text { Number of visits to: }\end{array}$ & $.409^{\S}$ & $.408^{\S}$ & -0.02 & -0.04 & 0.17 & 0.18 \\
\hline Doctor & $-.184^{\S}$ & $-.180^{\S}$ & -0.05 & -0.05 & 0.11 & 0.11 \\
\hline Case manager & $.597^{\S}$ & $.612^{\S}$ & $.314^{\S}$ & $.331^{\S}$ & -0.06 & -0.07 \\
\hline Dietitian & $-.214^{\S}$ & $-.215^{\S}$ & -0.08 & -0.08 & 0.02 & 0.02 \\
\hline DM educator & $.172^{\S}$ & $.183^{\S}$ & 0.06 & 0.08 & 0.19 & 0.20 \\
\hline Health educator & $.479^{\S}$ & $.491^{\S}$ & 0.10 & 0.10 & & \\
\hline Total visits & $.552^{\S}$ & $.569^{\S}$ & $.303^{\S}$ & $.321^{\S}$ & 0.11 & 0.11 \\
\hline
\end{tabular}

DM diabetes mellitus

(§) Statistically significant at $p<0.01$

specialized diabetes centers were shown to have poor diabetes control, with the ADA standards of diabetic care not met [24-26]. Several challenges to proper diabetes management in primary care setting have been described. These include insufficient patient education, inadequate patient adherence to medication, infrequent clinic visits, lack of social support, lack of home blood glucose monitoring, inadequate physician attitude and approach, and system barriers [27-29]. The integrated care program described in this study was designed to deal with all the above challenges.

The more frequent clinic visits were the only strategy to predict improved HbA1c levels independently in the current study. It appeared that several other components of the integrated care program that were correlated in univariate analysis to improved HbA1c levels, such as appropriate insulin types and doses, are only working through multiple clinic visits. Additionally, the contribution of clinical pharmacist, who worked as the case manager, may have improved insulin intensification that is not usually tackled by primary care physician [30, 31].

The integrated care program in the current study was associated with a considerably better lipid profile and a slight reduction in BP. Similar findings have been reported before with a considerable increase in the number of those with controlled total and LDL cholesterol and those with controlled BP after a multidisciplinary care $[15,19,32-$ 34]. However, the percentage changes in $\mathrm{BP}$ and, to a lesser extent, blood lipids in the current study were less remarkable compared with glycemic control, probably indicating the need for more involvement by dietitians, especially given that visits to dietitians were less frequent compared with other team members and were not different between the intervention and control groups. It should also be mentioned that the modest increase in body weight that was observed in the intervention group in this study and other studies may be related to increased insulin use among these patients [20].

Table 5 Best fitting multiple linear regression model for the improvement in the level of HbA1c after the intervention

\begin{tabular}{|c|c|c|c|c|c|c|c|}
\hline & \multicolumn{2}{|c|}{ Unstandardized Coefficients } & \multirow{2}{*}{$\begin{array}{l}\text { Standardized } \\
\text { Coefficients }\end{array}$} & \multirow[t]{2}{*}{ t-test } & \multirow[t]{2}{*}{$p$-value } & \multicolumn{2}{|c|}{ 95\% Confidence Interval for B } \\
\hline & B & Std. Error & & & & Lower & Upper \\
\hline Constant & 4.82 & 0.53 & & 9.09 & $<0.001$ & 3.77 & 5.86 \\
\hline Intervention vs control & 2.47 & 0.33 & 0.45 & 7.42 & $<0.001$ & 3.12 & 1.81 \\
\hline Total number of clinic visits & 0.07 & 0.02 & 0.22 & 3.66 & $<0.001$ & 0.03 & 0.11 \\
\hline
\end{tabular}

R-square $=0.35$, Model ANOVA: $\mathrm{F}=60.82, p<0.001$. Variables entered and excluded: age, sex, numbers of comorbidities, diabetes duration, insulin and oral medications, and insulin dose 


\section{Limitations and strengths}

The current study has the advantages of examining the effects of a multidisciplinary, multifaceted integrated care program on multiple outcomes and detecting the predictors of improved glycemic control, using an appropriate sample size and controlled design. Findings showed the impact of diabetes care conducted at the primary care level was an appropriate model of care. Nevertheless, we acknowledge some limitations, such differences between the two groups at enrollment. However, these differences were not in one direction, were less clinically meaningful, and probably had no effect on the study findings. For example, the patients in the control group, who had slightly more comorbidities, had slightly better glycemic control. Moreover, the differences in hypertension and dyslipidemia were not associated with differences in BP or blood lipids. The lack of blindness for both patients and care providers may contribute to bias in the results. We tried to minimize such effects by blinding the results to the outcomes assessors (i.e., labs workers and nurses). Additionally, further research encouraged to conduct to evaluate health economic during implementation of integrated care program through multidisciplinary team approach.

\section{Conclusions}

In conclusion, the implementation of a patient-tailored, integrated care program involving a multidisciplinary team approach, frequent clinic visits, and intensified insulin treatment in a primary care setting was associated with marked improvement in glycemic control, modest improvements in blood lipids, and a slight nonsignificant improvement in BP. Those with poor glycemic control are the highest group to benefit from such integrated care program.

\section{Additional file}

Additional file 1: Table S1. Diabetes treatment in the intervention and control groups. (DOCX 14 kb)

\section{Abbreviations}

BP: Blood pressure; FBG: Fasting Blood Glucose; T2DM: Type 2 Diabetes Mellitus; WHC: Wazarat Healthcare Center

\section{Acknowledgements}

We acknowledge students from the College of Pharmacy, King Saud University, who helped in the collection and entry of the data. We would like to acknowledge the Director of the Family and Community Medicine Department, Prince Sultan Military Medical City, in charge of WHC and the administrative team for their logistic support.

The content is solely the responsibility of the authors, who have all made substantial contributions to the study's conception and design, the analysis and interpretation of the data, the draft and revision of the article and the final approval of the version to be submitted.

\section{Funding}

This project did not receive any funding.

\section{Availability of data and materials}

The datasets used and/or analyzed during the current study available from the corresponding author on reasonable request.

\section{Authors' contributions}

TA and AT are the guarantors of the data. Author Contributions: TA, AT, and OA researched the data and wrote the manuscript; AM, AAlqahtani, and HAlqahtani researched the data and reviewed the manuscript; HAlkashan, AB, TE, AAlawad, AAlobaikan, AbR and AFA reviewed the manuscript and contributed to the discussion; $A M$ and $O A$ researched the data, reviewed and edited the manuscript, and conducted the statistical analyses. All authors read and approved the final manuscript.

\section{Ethics approval and consent to participate}

The Prince Sultan Military Medical City ethical committee ethically approved this study. The ethical approval number SA555 and the clinical trial is registered under the number ISRCTN83437562. This study was conducted in accordance to all Saudi regulations. The participants signed an informed consent for participation and publication.

\section{Consent for publication}

Not applicable.

\section{Competing interests}

The authors declare that they have no competing interests.

\section{Publisher's Note}

Springer Nature remains neutral with regard to jurisdictional claims in published maps and institutional affiliations.

Received: 9 March 2017 Accepted: 11 December 2017

Published online: 02 January 2018

\section{References}

1. Whiting DR, Guariguata L, Weil C, Shaw J. IDF diabetes atlas: global estimates of the prevalence of diabetes for 2011 and 2030. Diabetes Res Clin Pract. 2011:94(3):311-21.

2. Al-Nozha MM, Al-Maatouq MA, Al-Mazrou YY, Al-Harthi SS, Arafah MR, Khalil MZ, et al. Diabetes mellitus in Saudi Arabia. Saudi Med J. 2004;25(11):1603-10.

3. Al-Quwaidhi AJ, Pearce MS, Sobngwi E, Critchley JA, O'Flaherty M. Comparison of type 2 diabetes prevalence estimates in Saudi Arabia from a validated Markov model against the international diabetes federation and other modelling studies. Diabetes Res Clin Pract. 2014;103(3):496-503. doi:10. 1016/j.diabres.

4. Alhowaish AK. Economic costs of diabetes in Saudi Arabia. J Family Community Med. 2013;20(1):1-7.

5. Centers for Disease Control and Prevention. National diabetes fact sheet: general information and national estimates on diabetes in the United States, 2005. Atlanta: U.S. Department of Health and Human Services, Centers for Disease Control and Prevention; 2005.

6. The Diabetes Control and Complications Trial Research Group. The effect of intensive treatment of diabetes on the development and progression of long-term complications in insulin-dependent diabetes mellitus. N Engl J Med. 1993;329(14):977-86.

7. Buse JB, Ginsberg HN, Bakris GL, Clark NG, Costa F, Eckel R, et al. Primary prevention of cardiovascular diseases in people with diabetes mellitus: a scientific statement from the American Heart Association and the American Diabetes Association. Diabetes Care. 2007;30(1):162-72.

8. UK Prospective Diabetes Study Group. Tight blood pressure control and risk of macrovascular and microvascular complications in type 2 diabetes: UKPDS 38. BMJ. 1998;317(7160):703-13.

9. Costa J, Borges M, David C, Vaz CA. Efficacy of lipid lowering drug treatment for diabetic and non-diabetic patients: meta-analysis of randomised controlled trials. BMJ. 2006;332(7550):1115-24.

10. Davis TM, WA DCUEA, Bruce DG. Glycaemic levels triggering intensification of therapy in type 2 diabetes in the community: the Fremantle diabetes study. Med J Aust. 2006;184(7):325-8.

11. Brown LC, Johnson JA, Majumdar SR, Tsuyuki RT, McAlister FA. Evidence of suboptimal management of cardiovascular risk in patients with type 2 diabetes mellitus and symptomatic atherosclerosis. CMAJ. 2004;171(10): 1189-92. 
12. Willens $D$, Cripps R, Wilson A, Wolff K, Rothman R. Interdisciplinary team Care for Diabetic Patients by primary care physicians, advanced practice nurses, and clinical pharmacists. Clin Diab. 2011;29(2):60-8.

13. Ziemer DC, Miller CD, Rhee MK, Doyle JP, Watkins C Jr, Cook CB, et al. Clinical inertia contributes to poor diabetes control in a primary care setting. Diabetes Educ. 2005;31(4):564-71.

14. Codispoti C, Douglas MR, McCallister T, Zuniga A. The use of a multidisciplinary team care approach to improve glycemic control and quality of life by the prevention of complications among diabetic patients. J Okla State Med Assoc. 2004;97(5):201-4.

15. Antoline C, Kramer A, Roth M. Implementation and methodology of a multidisciplinary disease-state-management program for comprehensive diabetes care. Perm J. 2011;15(1):43-8.

16. Al Asmary SM, Al-Harbi T, Tourkmani AM, Al Khashan HI, Al-Qahtani $\mathrm{H}$, Mishriky A, et al. Impact of integrated care program on Glycemic control and cardiovascular risk in adult patients with type 2 diabetes. J Clin Outcomes Manage. 2013;20(8):356-63.

17. American Diabetes Association. Standards of medical care in diabetes-2013. Diabetes Care. 2013;36 Suppl 1:S11-66.

18. Joy SV. Clinical pearls and strategies to optimize patient outcomes. Diabetes Educ. 2008;34(Suppl 3):54S-9S.

19. Zwar NA, Hermiz O, Comino EJ, Shortus T, Burns J, Harris M. Do multidisciplinary care plans result in better care for patients with type 2 diabetes? Aust Fam Physician. 2007;36(1-2):85-9.

20. Rothman RL, Malone R, Bryant B, Shintani AK, Crigler B, Dewalt DA, et al. A randomized trial of a primary care-based disease management program to improve cardiovascular risk factors and glycated hemoglobin levels in patients with diabetes. Am J Med. 2005;118(3):276-84.

21. Zwar N, Hasan I, Hermiz O, Vagholkar S, Comino E, Harris M. Multidisciplinary care plans and diabetes-benefits for patients with poor glycaemic control. Aust Fam Physician. 2008;37(11):960-2.

22. Stratton IM, Adler Al, Neil HA, Matthews DR, Manley SE, Cull CA, et al. Association of glycaemia with macrovascular and microvascular complications of type 2 diabetes (UKPDS 35): prospective observational study. BMJ. 2000;321(7258):405-12.

23. Minshall ME, Roze S, Palmer AJ, Valentine WJ, Foos V, Ray J, et al. Treating diabetes to accepted standards of care: a 10-year projection of the estimated economic and health impact in patients with type 1 and type 2 diabetes mellitus in the United States. Clin Ther. 2005;27(6):940-50.

24. Alfadda AA, Bin Abdulrahman KA. Assessment of care for type 2 diabetic patients at the primary care clinics of a referral hospital. J Fam Commun Med. 2006;13(1):13-8.

25. Kharal M, Al-Hajjaj A, Al-Ammri M, Al-Mardawi G, Tamim HM, Salih SB, et al. Meeting the American diabetic association standards of diabetic care. Saudi J Kidney Dis Transpl. 2010;21(4):678-85.

26. Al-Arfaj IS. Quality of diabetes care at armed forces hospital, southern region, Kingdom of Saudi Arabia, 2006. J Family Community Med. 2010;17(3):129-34.

27. Nam S, Chesla C, Stotts NA, Kroon L, Janson SL. Barriers to diabetes management: patient and provider factors. Diabetes Res Clin Pract. 2011:93(1):1-9.

28. Chin MH, Cook S, Jin L, Drum ML, Harrison JF, Koppert J, et al. Barriers to providing diabetes care in community health centers. Diabetes Care. 2001; 24(2):268-74.

29. Elliott DJ, Robinson EJ, Sanford M, Herrman JW, Riesenberg LA. Systemic barriers to diabetes management in primary care: a qualitative analysis of Delaware physicians. Am J Med Qual. 2011;26(4):284-90.

30. Choe HM, Mitrovich S, Dubay D, Hayward RA, Krein SL, Vijan S. Proactive case management of high-risk patients with type 2 diabetes mellitus by a clinical pharmacist: a randomized controlled trial. Am J Manag Care. 2005;11(4):253-60.

31. Cuddihy RM, Philis-Tsimikas A, Nazeri A. Type 2 diabetes care and insulin intensification: is a more multidisciplinary approach needed? Results from the MODIFY survey. Diabetes Educ. 2011;37(1):111-23.

32. Kornelius E, Chiou JY, Yang YS, Lu YL, Peng CH, Huang CN. The diabetes shared care program and risks of cardiovascular events in type 2 diabetes. Am J Med. 2015 Sep;128(9):977-85.e3.

33. Chao J, Yang L, Xu H, Yu Q, Jiang L, Zong M. The effect of integrated health management model on the health of older adults with diabetes in a randomized controlled trial. Arch Gerontol Geriatr. 2015;60(1):82-8.

34. Russell AW, Baxter KA, Askew DA, Tsai J, Ware RS, Jackson CL. Model of care for the management of complex type 2 diabetes managed in the community by primary care physicians with specialist support: an open controlled trial. Diabet Med. 2013;30(9):1112-21.

\section{Submit your next manuscript to BioMed Central and we will help you at every step:}

- We accept pre-submission inquiries

- Our selector tool helps you to find the most relevant journal

- We provide round the clock customer support

- Convenient online submission

- Thorough peer review

- Inclusion in PubMed and all major indexing services

- Maximum visibility for your research

Submit your manuscript at www.biomedcentral.com/submit
Biomed Central 